\title{
The Effect of Irradiation Distance on Microhardness of Resin Composites Cured with Different Light Curing Units
}

Isil Cekic-Nagasa

Ferhan Egilmez ${ }^{b}$

Gulfem Ergunc

\section{ABSTRACT}

Objectives: The aim of this study was to compare the microhardness of five different resin composites at different irradiation distances $(2 \mathrm{~mm}$ and $9 \mathrm{~mm}$ ) by using three light curing units (quartz tungsten halogen, light emitting diodes and plasma arc).

Methods: A total of 210 disc-shaped samples $(2 \mathrm{~mm}$ height and $6 \mathrm{~mm}$ diameter) were prepared from different resin composites (Simile, Aelite Aesthetic Enamel, Clearfil AP-X, Grandio caps and Filtek Z250). Photoactivation was performed by using quartz tungsten halogen, light emitting diode and plasma arc curing units at two irradiation distances $(2 \mathrm{~mm}$ and $9 \mathrm{~mm}$ ). Then the samples $(\mathrm{n}=7 /$ per group) were stored dry in dark at $37^{\circ} \mathrm{C}$ for $24 \mathrm{~h}$. The Vickers hardness test was performed on the resin composite layer with a microhardness tester (Shimadzu HMV). Data were statistically analyzed using nonparametric Kruskal Wallis and Mann-Whitney U tests.

Results: Statistical analysis revealed that the resin composite groups, the type of the light curing units and the irradiation distances have significant effects on the microhardness values $(P<.05)$.

Conclusions: Light curing unit and irradiation distance are important factors to be considered for obtaining adequate microhardness of different resin composite groups. (Eur J Dent 2010;4:440-446)

Key words: Irradiation distance; Light curing units; Microhardness; Resin composites.

Research associate, Dental School of Technology, Hacettepe University, Ankara, Turkey.

b Research associate, Department of Prosthodontics, Faculty of Dentistry, Gazi University, Ankara, Turkey. c Associate Professor, Department of Prosthodontics, Faculty of Dentistry, Gazi University, Ankara, Turkey.

- Corresponding author: Dr. Isil Cekic-Nagas Address: Servi sokak 14/9

Kolej, Ankara, Turkey.

Phone: +903124323605

Fax: +90 3123102730

E-mail: isilcekicahacettepe.edu.tr isilcekicagmail.com

\section{INTRODUCTION}

In recent years, developments in resin chemistry and light curing units (LCU) have led to the production of resin composites with improved physical and mechanical properties. ${ }^{1-3}$ Furthermore, researchers have focused on the resin matrix monomers in order to improve properties like hardness, compressive strength, flexural strength and elastic modulus. ${ }^{4-7}$

The most traditional composites for restorative procedures are hybrid and microfilled, generally 
containing filler particles ranging from 0.5 to 4 $\mu \mathrm{m}$, and 0.02 to $0.09 \mu \mathrm{m}$, respectively. ${ }^{8}$ More recently, nanofilled and nanohybrid composites have been introduced with a filler size ranging from 5 to $100 \mathrm{~nm}$ in an attempt to have enhanced properties in both aesthetics and mechanical performance. ${ }^{4}$

The curing light technology has advanced with the introduction of high intensity quartz tungsten halogen (QTH), light emitting diodes (LED) and plasma arc (PAC) curing units.9,10 Until recently, conventional QTH LCUs were widely used to cure resin composites. ${ }^{11,12}$ These LCUs are susceptible to intensity output degradation with time as a result of the age of the bulb and its reflector, blistering and cracking of the filter, damage to the fiber-optic tips, because of repeated sterilization or heat generation. ${ }^{12}$ To overcome these problems, boosted versions of QTH, PAC and LED LCUs that possess higher light intensity and shorter polymerization cycles than conventional LCUs have been developed. 13,14 These high intensity LCUs may provide higher values of degree of conversion, and better physical and mechanical properties for the polymerized resin composites. ${ }^{15}$ Among these properties, testing microhardness is an efficient method to assess the relative degree of conversion of resins and, thus, the efficiency of the tested light curing sources. ${ }^{16,17}$ Additionally, the hardness of a material is a relative measure of its resistance to indentation when a specific and constant load is applied. Thus, hardness might be described as a measure of the ability of a material to resist indentation or scratching. ${ }^{16}$

An adequate polymerization of resin composites is crucial for the ultimate success and longevity of the restoration. ${ }^{17}$ It depends not only on the irradiance of the curing light and irradiation time but also on the distance of the light tip from the tooth-restorative material. ${ }^{18,19}$ Because the light intensity diminishes as the tip of the source light moves away from the resin composite's surface, the light-curing tip unit should be in direct contact with the restoration's surface. However, sometimes cavity design does not allow the polymerization within this distance. ${ }^{20}$

On these grounds, the purpose of this investigation was to evaluate the effect of various light-tip distances (2 $\mathrm{mm}$ and $9 \mathrm{~mm}$ ) on Vicker's microhardness (VHN) values of different resin composites cured with QTH, LED and PAC LCUs.
The null hypothesis tested was that the type and distance of the LCUs from the restoration would affect the VHN microhardness of the tested resin composites.

\section{MATERIALS AND METHODS}

Specimen preparation

Five commercial light-cured resin composites were used in this study (Table 1). Shade A2 was chosen to minimize the effect of color on the photopolymerization process. ${ }^{21}$ The experimental setup is given in Figure 1. Disc-shaped specimens, $2 \mathrm{~mm}$ in height and $6 \mathrm{~mm}$ in diameter, were prepared according to the manufacturers' instructions by packing the resin composites into circular polytetrafluoroethylene moulds. A polyethylene film was placed on the top and base of the resin composite materials. Additionally, a $1 \mathrm{~mm}$ thick glass slide was seated on the top of the mould to exclude excessive resin composite material and to eliminate possible air bubbles. Then the samples were irradiated from the top through the polyethylene films using a quartz tungsten halogen light (QTH, $1000 \mathrm{~mW} / \mathrm{cm}^{2}$, Blue Swan Digital, Dentanet, Ankara, Turkeyl for $20 \mathrm{~s}$, a light-emitting diode (LED, $1200 \mathrm{~mW} / \mathrm{cm}^{2}$, Elipar Freelight 2, 3M Espe, USA) for $20 \mathrm{~s}$ and a plasma arc (PAC, 2250 \pm 50 $\mathrm{mW} / \mathrm{cm}^{2}$, PlasmaStar, SP-2000, Monitex, Taiwan) for $10 \mathrm{~s}$ at different irradiation distances $12 \mathrm{~mm}$ and $9 \mathrm{~mm}$ ). Additionally, the power outputs of the LCUs at $2 \mathrm{~mm}$ and $9 \mathrm{~mm}$ were measured by a radiometer (Cure Rite, EFOS, New York NY, USA). The curing tip distances were controlled via the use of metal rings. After light polymerization, the specimens were stored dry in dark at $37^{\circ} \mathrm{C}$ for 24 $\mathrm{h}$ before testing.

\section{Vicker's microhardness test}

A total of 210 samples were polished under wet conditions with 220,360, and 600 grit silicon carbide grinding paper (FEPA, Federation of European Producers of Abrasives, Paris, Francel and placed on the platform of the tester with the surface being tested facing the diamond indenter ( $n=7 /$ per group). The VHN test was performed on the cement layer with a microhardness tester (Shimadzu HMV; Shimadzu Corporation, Tokyo, Japan) with $200 \mathrm{~g}$ of load application for $15 \mathrm{sec}$ onds. Three indentations taken from each sample were not closer than $1 \mathrm{~mm}$ to the margin and were 
averaged to determine the hardness value of each sample. Vicker's hardness values were converted into microhardness values by the machine. All specimen preparations and VHN measurements were performed by the same operator in a darkened environment.

\section{Statistical analysis}

Statistical analysis was performed by Statistical Package for Social Sciences (SPSS) 11.5 soft-

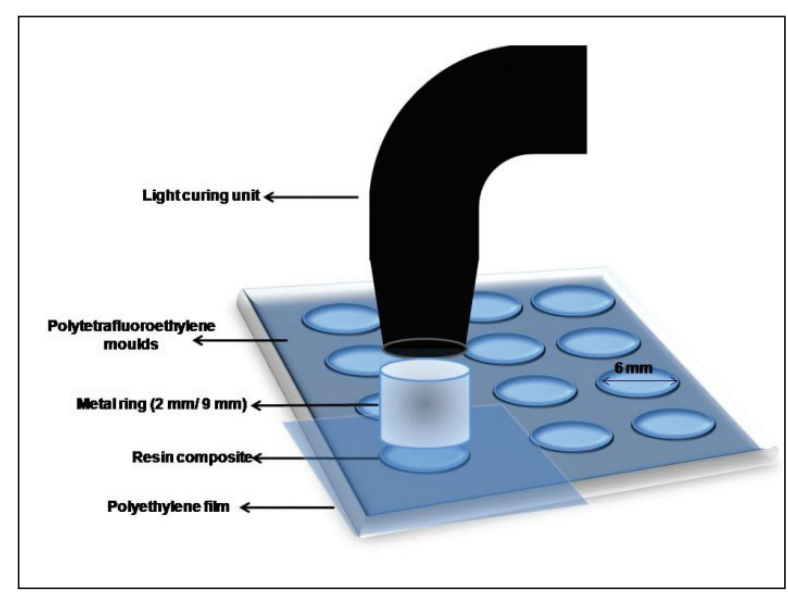

Figure 1. Schematic illustration of specimen preparation.

Table 1. Test materials and their composition according to manufacturers.

\begin{tabular}{|c|c|c|c|c|c|c|}
\hline Trade & $\begin{array}{l}{ }^{*} \text { Chemical } \\
\text { composition }\end{array}$ & Type & $\begin{array}{c}\text { Filler } \\
\text { (filler size) }\end{array}$ & $\begin{array}{l}\text { Filler content } \\
\text { (wt } \%)\end{array}$ & Lot number & Manufacturer \\
\hline Simile & $\begin{array}{l}\text { Difunctional } \\
\text { methacrylate of } \\
\text { aPCBIS-GMA, } \\
\text { 'Bis-GMA, } \\
\text { 'UDMA, } \\
\text { 'HDDMA }\end{array}$ & Nano-hybrid & $\begin{array}{l}\text { Barium boro-silicate } \\
\text { glass, } \\
\text { (0.04-0.7 } \mu \mathrm{m}), \text { nanopar- } \\
\text { ticulate silica, zirconium } \\
\text { silicate (Nanofiller, } \\
5-20 \mathrm{~nm})\end{array}$ & $75 \%$ & 144063 & $\begin{array}{c}\text { Pentron Clinical Tech- } \\
\text { nologies, Wallingford, } \\
\text { USA }\end{array}$ \\
\hline Clearfil AP-X & $\begin{array}{c}\text { 'Bis-GMA, } \\
\text { eTEGDMA, } \\
\text { Camphorquinone }\end{array}$ & $\begin{array}{l}\text { Micro } \\
\text { hybrid }\end{array}$ & $\begin{array}{c}\text { Barium glass, silica, } \\
\text { colloidal silica, } \\
\text { silicon } \\
\text { dioxide } \\
(0.1-15 \mu \mathrm{m})\end{array}$ & $85.5 \%$ & 454BA & $\begin{array}{l}\text { Kuraray Medical Inc, } \\
\text { Tokyo, Japan }\end{array}$ \\
\hline Grandio caps & $\begin{array}{c}\text { 'Bis-GMA, } \\
\text { 'UDMA, } \\
\text { 'TEGDMA, } \\
\text { dimethacrylate }\end{array}$ & Nano-hybrid & $\begin{array}{l}\text { Glass-ceramic (Mi- } \\
\text { crofiller, } 1 \mu \mathrm{m} \text { ), SiO2 } \\
\text { (Nanofiller, } \\
20-60 \mathrm{~nm} \text { ) }\end{array}$ & $87 \%$ & $7 \mathrm{HJ}$ & $\begin{array}{c}\text { Voco GmbH Cuxhaven } \\
\text { Germany }\end{array}$ \\
\hline $\begin{array}{l}\text { Filtek Z } 250 \\
\text { Universal } \\
\text { Restorative }\end{array}$ & $\begin{array}{c}\text { 'UDMA, }{ }^{9} \text { BisEMA, } \\
\text { 'BisGMA, } \\
\text { eTEGDMA }\end{array}$ & Microhybrid & $\begin{array}{c}\text { Zirconia/silica particles } \\
(0.01-3.5 \mu \mathrm{m})\end{array}$ & $82 \%$ & 20051212 & $\begin{array}{c}\text { 3M Espe, St. Paul, } \\
\text { MN, USA }\end{array}$ \\
\hline
\end{tabular}

*Information provided by manufacturers.

aPCBisGMA: polycarbonate bisphenol A glycerol dimethacrylate, "BisGMA: bisphenol A glycerol dimethacrylate, cUDMA: urethane dimethacrylate, ${ }^{\mathrm{d} H D D M A}$ : 1,6 hexanediol dimethacrylate, ${ }^{e}$ TEGDMA: triethylene glycol dimethacrylate, 'EBPADMA: ethoxylated bisphenol A dimethacrylate, ${ }^{9}$ BisEMA: ethoxylated bisphenol A dimethacrylate. ware (SPSS Inc., Chicago, IL, United States). The Shapiro Wilk test showed that VHN values of the resin composites were not normally distributed. Data were expressed as median $\left(25^{\text {th }}-75^{\text {th }}\right)$ percentiles. The differences among the resin composites and LCU groups were evaluated by using Kruskal Wallis test, and the irradiation distances were compared by Mann Whitney $U$ test. If the $p$ value from Kruskal Wallis test statistics was statistically significant, multiple comparison tests were used to know which group differed from each other $(\mathrm{P}<.05)$. All possible subgroup analyses with Bonferroni Adjustment were applied to control Type I error.

\section{RESULTS}

The median VHN values and $\left(25^{\text {th }}-75^{\text {th }}\right)$ percentiles for samples are shown in Table 2. The results of the VHN test indicated that significant differences were observed based on the type of resin composite $(\mathrm{P}<.05)$ and the LCU $(\mathrm{P}<.05)$. Moreover, irradiation distances had significant effects on microhardness values of resin composites $(P<.05)$. 
The statistical ranking for VHN median values among resin composites was obtained as follows: Aelite Aesthetic Enamel Simile < Filtek Z250 < Clearfil AP-X $\sim$ Grandio caps ( $P<$.05). Clearfil AP-X cured with LED at a distance of $2 \mathrm{~mm}$ yielded the highest median VHN value (119 VHN) whereas Simile cured with QTH LCU at a distance of $9 \mathrm{~mm}$ presented the lowest value overall (61.1 VHN) (Table 2). In addition, QTH LCU presented similar VHN values with PAC LCU and lower values than LED LCU $(P<.05)$. Additionally, in all groups except Filtek Z250 and Grandio Caps cured with PAC, and Aelite Aesthetic enamel cured with QTH, the VHN values of resin composites decreased with the increase in irradiation distance (Table 2).

\section{DISCUSSION}

In the present study, the hardening of resin composites was investigated to ensure the efficacy of different LCUs. Previous studies showed hardness as a good indicator of conversion of double bonds ${ }^{22,23}$ and was therefore used in the present study as an indirect measurement of conversion. It was also reported that hardness was useful in determining the development of the mechanical properties of resin composites during their polymerization reaction, and that there was a direct correlation between degree of conversion and hardness development during polymerization, as a consequence of the increase in stiffness and strength of the material. ${ }^{24-27}$

Conflicting results are often indicated in the literature when the effects of different LCUs on resin composites are reported. ${ }^{28-30}$ This might be explained by the differences between irradiation protocols used, especially regarding the intensities. ${ }^{31}$ Previous studies reported that LED LCU cured resin composites as well or better than some QTH LCUs. ${ }^{17,32-34}$ Furthermore, a previous study by Alves et $\mathrm{al}^{35}$ compared the hardness of resin composite restorations using different LCUs and concluded that the LED LCU showed greater hardness than the PAC LCU. However, no significant differences between the QTH and other LCUs were detected in that study. Similar to these previous studies, LED LCU presented higher hardness values than QTH and PAC in the present study. Additionally, hardness values of PAC LCU were comparable to those of QTH LCU.

In a previous study, the effects of resin composite composition and irradiation distance on the performance of curing lights were investigated

Table 2. Median values and $\left(25^{\text {th }}-75^{\text {th }}\right)$ percentiles for Vicker's microhardness (VHN) of the resin composites tested.

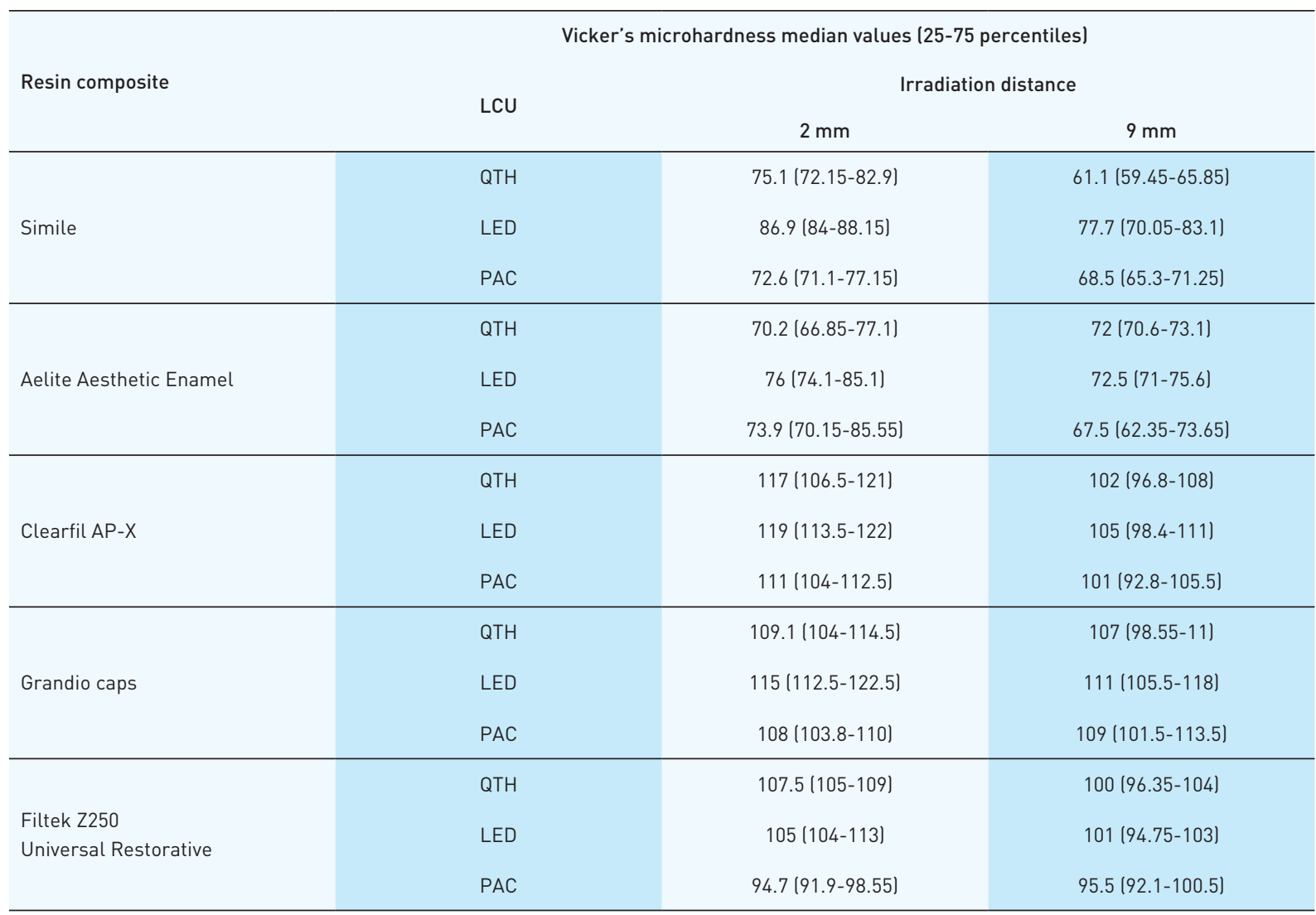


and the results were explained by a formula that indicated the total energy that reached the resin composite. ${ }^{21}$ With reference to that formula, in the present study, when the PAC LCU delivered 2200 $\mathrm{mW} / \mathrm{cm}^{2}$ and was used for $10 \mathrm{~s}$, the resin composite might have received $22 \mathrm{~J} / \mathrm{cm}^{2}$. Moreover, when both the QTH LCU which delivered $1000 \mathrm{~mW} / \mathrm{cm}^{2}$ and the LED LCU which delivered $1200 \mathrm{~mW} / \mathrm{cm}^{2}$ were used for $20 \mathrm{~s}$, the resin composites might have received $20 \mathrm{~J} / \mathrm{cm}^{2}$ and $24 \mathrm{~J} / \mathrm{cm}^{2}$, respectively lassuming that the same wavelengths are delivered). This could provide an explanation as to why no major differences in microhardness values of resin composites cured with different LCUs were seen.

The present experimental results support the hypothesis that the type of LCU and the LCU tip distance from the restoration affect the VHN microhardness of resin composites. To represent clinical distances, the composites were irradiated at $2 \mathrm{~mm}$ and $9 \mathrm{~mm}$ away from the LCU. A previous study by Thomé et $\mathrm{al}^{20}$ reported that adequate polymerization demands light intensities greater than 250-300 $\mathrm{mW} / \mathrm{cm}^{2}$, increment thickness of 2 $\mathrm{mm}$ or less and a distance no greater than $6 \mathrm{~mm}$ between the LCU and the resin composite's surface. However, if there is an inability to place an LCU tip near the restorative material, this might reduce intensity and provide a lower degree of polymerization. ${ }^{36}$ In addition, Caldas et al ${ }^{37}$ evaluated the effect of irradiation distance 10,6 and 12 $\mathrm{mm}$ ) on hardness of resin composites in another study and found that hardness values of the resin composites decreased when the light tip distance increased. Similarly, in the current study, the VHN values of resin composites irradiated with LCU tip at $9 \mathrm{~mm}$ distance were lower than the values cured with LCU tip at $2 \mathrm{~mm}$ distance lexcept Filtek Z250 and Grandio Caps cured with PAC, and Aelite Aesthetic enamel cured with QTH) .

As for the comparison of microhardness values of the resin composites in the present study, Grandio caps and Clearfil AP-X exhibited higher VHN than Filtek Z250, Aelite Aesthetic Enamel and Simile. Despite being nanofilled composites, Aelite Aesthetic Enamel and Simile did not achieve the values that Grandio did. While Grandio has higher filler load (87\%) than Aelite Aesthetic Enamel and Simile $(73 \%$ and $75 \%$, respectively), these resin composites (Aelite Aesthetic enamel and Simile) have similar nanofiller size with $(40$ $\mathrm{nm}$ and 5-20 nm, respectively) Grandio (20-60 nm). This might indicate that the size of the fillers may not be the determinative factor in hardness property when there is an important difference in filler loads. Therefore, differences in the organic matrix and the filler load (Table 1) might be responsible for the following ranking (Aelite Aesthetic Enamel Simile < Filtek Z250 < Clearfil AP-X Grandio caps). Similarly, a previous study by Mota et al ${ }^{38}$ investigated the knoop microhardness of five nanofilled composites and correlated the higher knoop microhardness test values of Grandio and Supreme with their filler contents by weight. Besides, an investigation by $\mathrm{Xu}^{39}$ which evaluated the effect of fillers on composite properties showed a strong positive correlation between the weight filler content and the microhardness values of composites.

In conclusion, from a clinical standpoint, polymerization of resin composites is important in order to obtain sufficient surface hardness. Moreover, the results of this experiment must be brought into relation with conversion data. Further in vitro tests and long-term clinical trials are needed to investigate the effect of microhardness and degree of conversion on the longevity of resin composites.

\section{CONCLUSIONS}

Within the limitations of this in-vitro study, the following conclusions could be drawn:

- High-power LED LCUs might be considered more effective than QTH and PAC LCUs for polymerization of the resin-based materials.

- Resin composites showed different VHN values, depending on their composition, filler types and polymerization method.

- The VHN values of almost all resin composites decreased with the increased irradiation distance, except Filtek Z250 and Grandio Caps cured with PAC, and Aelite Aesthetic enamel cured with QTH.

\section{REFERENCES}

1. Aguiar FH, Braceiro AT, Ambrosano GM, Lovadino JR. Hardness and diametral tensile strength of a hybrid composite resin polymerized with different modes and immersed in ethanol or distilled water media. Dent Mater 2005;21:10981103. 
2. Neumann MG, Miranda WG Jr, Schmitt CC, Rueggeberg FA, Correa IC. Molar extinction coefficients and the photon absorption efficiency of dental photoinitiators and light curing units. J Dent 2005;33:525-532.

3. F e Silva AL, Pereira GD, Dias CT, Sartini Paulillo LA. Effect of the composite photoactivation mode on microtensile bond strength and Knoop microhardness. Dent Mater 2006;22:203-210.

4. Papadogiannis DY, Lakes RS, Papadogiannis Y, Palaghias G, Helvatjoglu-Antoniades M. The effect of temperature on the viscoelastic properties of nano-hybrid composites. Dent Mater 2008;24:257-266.

5. Peutzfeldt A. Resin composites in dentistry: the monomer systems. Eur J Oral Sci 1997;105:97-116.

6. Beun S, Glorieux T, Devaux J, Vreven J, Leloup G. Characterization of nanofilled compared to universal and microfilled composites. Dent Mater 2007;23:51-59.

7. Kim Y, Kim CK, Cho BH, Son HH, Um CM, Kim OY. A new resin matrix for dental composite having low volumetric shrinkage. J Biomed Mater Res B Appl Biomater 2004;70:8290.

8. de Moraes RR, Ribeiro Ddos S, Klumb MM, Brandt WC, Correr-Sobrinho L, Bueno M. In vitro toothbrushing abrasion of dental resin composites: packable, microhybrid, nanohybrid and microfilled materials. Braz Oral Res 2008;22:112-118.

9. Aravamudhan K, Rakowski D, Fan PL. Variation of depth of cure and intensity with distance using LED curing lights. Dent Mater 2006;22:988-994.

10. Santos GC Jr, El-Mowafy O, Rubo JH, Santos MJ. Hardening of dual-cure resin cements and a resin composite restorative cured with QTH and LED curing units. J Can Dent Assoc 2004;70:323-328.

11. Jung $H$, Friedl KH, Hiller KA, Furch H, Bernhart S, Schmalz G. Polymerization efficiency of different photocuring units through ceramic discs. Oper Dent 2006;31:68-77.

12. Leonard DL, Charlton DG, Roberts HW, Cohen ME. Polymerization efficiency of LED curing lights. J Esthet Restor Dent 2002:14;286-295.

13. Fleming GJ, Khan S, Afzal O, Palin WM, Burke FJ. Investigation of polymerization shrinkage strain, associated cuspal movement and microleakage of MOD cavities restored incrementally with resin-based composite using an LED light curing unit. J Dent 2007:35;97-103.

14. Jain P, Pershing A. Depth of cure and microleakage with high-intensity and ramped resin-based composite curing lights. J Am Dent Assoc 2003:134;1215-1223.
15. Soares LE, Liporoni PC, Martin AA. The effect of soft-start polymerization by second generation LEDs on the degree of conversion of resin composite. Oper Dent 2007:32;160165.

16. Miranda CB, Pagani C, Bottino MC, Benetti AR. A comparison of microhardness of indirect composite restorative materials. J Appl Oral Sci 2003:11;157-161.

17. Ceballos L, Fuentes M V, Tafalla H, Martínez A, Flores J, Rodríguez J. Curing effectiveness of resin composites at different exposure times using LED and halogen units. Med Oral Patol Oral Cir Bucal 2009:14;E51-E56.

18. Rueggeberg FA, Caughman WF, Curtis JW Jr. Effect of light intensity and exposure duration on cure of resin composite. Oper Dent 1994:19;26-32.

19. Yazici AR, Müftü A, Kugel G. Temperature rise produced by different light-curing units through dentin. J Contemp Dent Pract 2007:8;21-28.

20. Thomé T, Steagall W Jr, Tachibana A, Braga SR, Turbino $M L$. Influence of the distance of the curing light source and composite shade on hardness of two composites. J Appl Oral Sci 2007:15;486-491.

21. Price RB, Felix CA, Andreou P. Effects of resin composite composition and irradiation distance on the performance of curing lights. Biomaterials 2004:25;4465-4477.

22. David JR, Gomes OM, Gomes JC, Loguercio AD, Reis A. Effect of exposure time on curing efficiency of polymerizing units equipped with light-emitting diodes. J Oral Sci 2007:49;19-24.

23. Bouschlicher MR, Rueggeberg FA, Wilson BM. Correlation of bottom-to-top surface microhardness and conversion ratios for a variety of resin composite compositions. Oper Dent 2004:29;698-704.

24. Reges RV, Moraes RR, Correr AB, Sinhoreti MA, CorrerSobrinho L, Piva E, Nouer P R. In-depth polymerization of dual-cured resin cement assessed by hardness. J Biomater Appl 2008:23;85-96.

25. Sinhoreti MA, Manetta IP, Tango RN, Iriyama NT, Consani $\mathrm{RL}$, Correr-Sobrinho L. Effect of light-curing methods on resin cement Knoop hardness at different depths. Braz Dent J 2007:18;305-308.

26. Santos GB, Medeiros IS, Fellows CE, Muench A, Braga RR. Composite depth of cure obtained with QTH and LED units assessed by microhardness and micro-Raman spectroscopy. Oper Dent 2007:32;79-83.

27. Kurachi C, Tuboy AM, Magalhães DV, Bagnato VS. Hardness evaluation of a dental composite polymerized with experimental LED-based devices. Dent Mater 2001:17;309315. 
28. Oberholzer TG, Du Preez, IC, Kidd M. Effect of LED curing on the microleakage, shear bond strength and surface hardness of a resin-based composite restoration. Biomaterials 2005:26;3981-3986.

29. Bennett AW, Watts DC. Performance of two blue lightemitting-diode dental light curing units with distance and irradiation-time. Dent Mater 2004:20;72-79.

30. Lohbauer U, Rahiotis C, Krämer N, Petschelt A, Eliades G. The effect of different light-curing units on fatigue behavior and degree of conversion of a resin composite. Dent Mater 2005:2;608-615.

31. Cekic I, Ergun G, Lassila LV, Vallittu PK. Ceramic-dentin bonding: effect of adhesive systems and light curing units. J Adhes Dent 2007:9;17-23.

32. Mobarak E, Elsayad I, Ibrahim M, El-Badrawy W. Effect of LED light-curing on the relative hardness of tooth-colored restorative materials. Oper Dent 2009:34;65-71.

33. Peris AR, Mitsui FH, Amaral CM, Ambrosano GM, Pimenta $L A$. The effect of composite type on microhardness when using quartz-tungsten-halogen (QTH) or LED lights. Oper Dent 2005:30;649-654.

34. Mills RW, Uhl A, Blackwell GB, Jandt KD. High power light emitting diode (LED) arrays versus halogen light polymerization of oral biomaterials: Barcol hardness, compressive strength and radiometric properties. Biomaterials 2002:23;2955-2963.

35. Alves EB, Alonso RC, Correr GM, Correr AB, de Moraes RR, Sinhoreti MA, Correr-Sobrinho L. Transdental photoactivation technique: hardness and marginal adaptation of composite restorations using different light sources. Oper Dent 2008:33;421-425.

36. Sfondrini MF, Cacciafesta V, Scribante A, Boehme A, JostBrinkmann PG. Effect of light-tip distance on the shear bond strengths of resin-modified glass ionomer cured with high-intensity halogen, light-emitting diode, and plasma arc lights. Am J Orthod Dentofacial Orthop 2006:129;541546.

37. Caldas DB, de Almeida JB, Correr-Sobrinho L, Sinhoreti $M A$, Consani S. Influence of curing tip distance on resin composite Knoop hardness number, using three different light curing units. Oper Dent 2003:28;315-320.

38. Mota EG, Oshima HM, Burnett LH Jr, Pires LA, Rosa RS. Evaluation of diametral tensile strength and Knoop microhardness of five nanofilled composites in dentin and enamel shades. Stomatologija 2006:8;67-69.

39. Xu HH. Dental composite resins containing silica-fused ceramic single-crystalline whiskers with various filler levels. J Dent Res 1999:78;1304-1311. 